THE Fapan Gazette learns that as an encouragement to the producers of tea, silk, and cocoons, it has been resolved by the Government to hold an exhibition of these articles in the Machigwai-sho at Yokohama. Foreigners and native dealers are not to be allowed to exhibit, as the scheme is devised entirely for the benefit of producers and manufacturers.

GOLD-BEARING quartz has lately been discovered at Sarugoye in the Yamato district of Japan.

THE Golos reports the discovery in the district of Perejaslavl, Pultowa Government, of 370 flint arrow-heads, a number of bones of men and animals, fragments of earthenware, and bronze objects.

THE Annual Report of the Goole Scientific Society for 1878-9 records satisfactory progress. As the result of a rule admitting ladies, twenty-one have joined the society.

The Hull Literary and Philosophical Society, to judge from the Report for 1878.9 , seems to be doing a great variety of good work in their district by means of lectures, papers, classes, \&c. The Society is in a flourishing condition as to members and funds, and has added, during the session, a Microscopical and a Geological Section.

THE additions to the Zoological Society's Gardens during the past week include two Red and Yellow Macaws (Ara chloroptera), a Red and Blue Macaw (Arca macao), a Blue and Yellow Macaw (Ara ararauna) from South America, a Common Trumpeter (Psopicic crepitans) from Demerara, presented by Mr. Chas. Fricker ; two Golden Eagles (Aquila chrysä̈tos) from Scotland, presented by Mrs. A. H. Browne; a Geoffroy's Marmoset (Midas geoffroii) from Panama, purchased; a Stanley Crane (Tetrapteryx paradisca) from South Africa, received in exchange; a Bay. Antelope (Cephalophus dorsalis) from West Africa, i eposited; a Peacock Pheasant (Polyplectron chinquisis) two Black-crested Cardinals (Guberratrix cristatella), two Geoffroy's Doves (Peristerc geoffroii), bred in the Gardens.

\section{THE EOZÖON CANADENSE}

$W^{E}$ have received the following communications on this subject :-

I shall be glad to be allowed to ask your readers to suspend. their judgment in the matter of Eozöon, until the appearance of the full and complete memoir, based (I venture to say) upon investigations far more comprehensive than those of Prof. Moebius-upon which I am now engaged, in conjunction with my friend Prof. Dawson. But as the production of this memoir will necessarily be a work of considerable time, on account of the elaborate illustrations it will require, I would now offer the following brief remarks on that part of Prof. Moebius's discussion which relates to the so-called "canal-system."

Among the numerous beantiful figures which Prof. Moebius has given of sections of the "canal-system," there is not one which represents what I described and figured, when I last wrote on the subject (Ann. of Nat. Hist., June, 1874, plate xix.), as "what appears to be the typical mode of its distribution." Nor is this brought out in any of the small number of figures which Prof. Moebius gives of the internal casts obtained by decalcification. Now to any one who will picture to himself how imperfect would be any conception he could form of the ramification of a tree, by taking a number of sections of its stem and system of branches through different planes, it must be obvious that "internal casts," in relief, when well preserved, will give a representation of the canal-system, which must be much truer than any conception can be that is based on a comparison of sections only; and that, in fact, it is only when the sections are interpreted by such solid models, that the real forms and relations of these "canal-systems" can be made out.

Having been kindly furnished by Prof. Dawson some months ago, with a large amount of new material, consisting of numerous specimens of Eozöon, obtained from different localities and in different states of mineralisation, I am now able to assert with confidence that the peculiar distribution described and figured by me from the actual specimens (one of which has been in Prof, Moebius's own possession) five years ago, ${ }^{I}$ is the regular and characteristic "canal-system" of Eozöon. For my cabinet now contains hundreds of examples of it, both in transparent sections and in the solid models obtained by decalcification; and these last, in partially "dolomitised" specimens of Eozöon, show the following singular peculiarities, which do not seem to have fallen under Prof. Moebius's observation. When a band of dolomite runs through the calcite layers, (I) the "canal systems" in its neighbourhood are very commonly filled with dolomite, instead of with serpentine; (2) in one and the same canal-system, some of the branches are often filled with dolomite, and others with serpentine; while (3) individual branches are often partly filled with one mineral and partly with the other.

How these facts can be explained, except by the pre-existence of a system of canals in the calcareous layers into which these minerals have penetrated, I must confess myself unable to conceive; and that they thus afford demonstrative evidence of a structure which cannot be otherwise than organic is not merely my own opinion, but that of such accomplished petrologists as Prof. Geikie, who has been for some years engaged in the microscopic study of the metamorphic rocks of Scotland, and Prof. Bonney, who has been similarly studying the Cornish serpentines.

Whether, when taken in connection with the general structure of the oroanism, these "canal-systems" indicate its Foramini feral affinities is, of course, an altogether different matter. To Prof. Moebius the difference seems greater than the resemblance but it is noteworthy that his comparisons are limited to types examined by himseif, and do not extend to Calcarina, in whose "canal-system" Di: Dawson and I recognise the nearest ap. proach to that of Eczoön. To myself, as to the late Prof. Max Schultze, ${ }^{2}$ the resemblance seems greater than the difference. And as the several "canal-systems" of Notmmutina, Polysto. mella, Calcarina, Tinoporus, and Cycloclypeus (all originally worked out by myself) differ from each other in plan, I camnot regard it as a valid argtument against the foraminiferal affinities of Eozöon that its canal-system has a plan of its own. Surely Prof. Moebius would not deny the foraminiferal characters to any new recent type that the Challengtr or any other collection may yield, if it shoutd show a plan of canal-system different from any yet known, and approximating to that of Eozöon.

That in its general plan of growth (to which the distribution of the canal-system is intimately related) Eozöon differs from all recent Fordminifera at present known camnot be regarded as a proof of its non-foraminiferal character by any who have fully studied the very wide range of forms which that group compiehends, including the numerous indefinite "arenaceous" types, whose import is only now beginning to be understood by those who have the best opportunities of studying them.

$I$ would suggest this further consideration: If we are to relegate to the nineral kingdom every supposed fossil that does not conform to any known existing type, we must expunge not only Eozöon, but Stromatopora-to say nuthing of many other fossils whose place no one has yet been able to assign with certainty. Now, is Prof. Moebius prepared to say that Stromatopora is a "pseudomorpli," because one zoologist thinks it a coral, another a sponge, and another a forauninifer? On bis method of "differences" it is clearly neither one of these; and must, as he says of Eozöon, be either shut out of the animal kingdom altogether", or be made to constitute a sub-kingdom in itself. To myself it appears more philosophical to suppose that such "archaic" types combined in themselves characters which were afterwards specialised as those of distinct gromps. And following this clue, I find in the chambered structure of Eoröon, and in its general relations to the canal-system traversing its calcareous layers, points of essential conformity to the group of Foraminifera, which seem to me far to outweigh the differences of detail by which Prof. Moebius has been led to the opposite conclusion.

I limit myself to this special point, because an excellen general criticism of Prof. Moebius's memoir, from the pen of Dr. Dawson, has already appeared in the American fournal of Science; and I hope that as you have given so much prominence to the views put forth by Prof. Moebius, you will do Dr. Dawson

I I think it rather hard that an early diagram of mine should be cited, and made the subject of adverse criticism, while those more recent representations of actual structures are ignored.

ations of actual structures are ignored. ind behind him for publication an elaborate and beautifully int of the resemblance of its "canal-system" to that of existing types. 
and myself the justice of placing before your readers his stateinent of objections to them, in which I fully concur.

Fereafter I think I shall be able to show that the "cumulative argument in favour of the organic character of Eozöon is as strong as that of the human origin of the "flint implements." Any one of the fractures that has given to these their characteristic forms, might have been accidental ; and yet it is impossible to conceive that any number of such flints can have been so shaped "by accident." London, July 28

The following is the comunication from Principal Dawson referred to by Dr. Carpenter :-

Frozöon canadense has, since the first announcement of its dis. covery by Logan in $\times 859$, attracted much attention, and has been very thoroughly investigated and discussed, and at present its organic character is generally admitted. Still its claims are ever and anon disputed, and as fast as one opponent is disposed of another appears. This is in great part due to the fact that so few scientific men are in a position fully to appreciate the evidence respecting it. Geologists and mineralogists look upon it with suspicion, partly on account of the great age and crystalline structure of the rocks in which it occurs, partly because it is associated with the protean and disputed mineral serpentine, which some regard as eruptive, some as metamorphic, some as pseudomorphic, while few have had enough experience to enable them to understand the difference between those serpentines which occur in limestones, and in such relations as to prove their contemporaneous deposition, and those which may have resulted from the hydration of olivine or similar changes. Only a few also have learned that Eozöon is only sometimes associated with serpentine, but that it occurs also mineralised with loganite, pyroxene, dolomite, or even earthy limestone, though the serpen. tinous specimens have attracted the most attention, owing to their beauty and abundance in certain localities. The biologists on the other hand, even those who are somewhat familiar with foraminiferal organisms, are little acquainted with the appearance of these when mineralised with silicates, traversed with ininute nineral veins, faulted, crushed, and partly defaced, as is the case with most specimens of Eozöon. Nor are they willing to admit the possibility that these ancient organisms may have presented a much more generalised and less definite structure than their modern successors. Worse, perhaps, than all these, is the circumstance that dealers and injudicious amateurs have intervened, and have circulated specimens of Eozöon, in which the structure is too imperfectly preserved to admit of its recognition, or even mere fragments of serpentinous limestone, without any structure whatever. I have seen in the collections of dealers, and even in public museums, specimens labelled "Eozöon cazzadense" which have as little claim to that designation as a chip of limestone has to be called a coral or a crinoid.

The meinoir of Prof. Moebius affords illustrations of some of these clifficulties in the study of Eozöon. Prof. Moebius is a zoologist, a good microscopist, fairly acquainted with modern foraminifera, and a conscientious observer; but he has had no means of knowing the geolugical relations and mode of occurrence of Eozöon, and he has had access merely to a limited number of specimens mineralised with serpentine. These he has elaborately studied, and has made careful drawings of portions of their structures, and has described these with some degree of accuracy; and his memoir has been profusely illustrated with figures on a large scale. This, and the fact of the memoir appearing where it does, convey the impression of an exhaustive study of the subject, and since the conclusion is adverse to the organic character of Eozöon, this paper may be expected, in the opinion of many not fully acquainted with the evidence, to be regarded as a final decision against its animal nature: Yet, however commendable the researches of Moebius may be, when viewed as the studies of a naturalist desirous of satisfying himself on the evidence of the material he may have at command, they furnish only another illustration of partial and imperfect investigation, quite unreliable as a verdict on the questions in hand. The following considerations will serve to indicate the weak points of the memoir:-

I. A number of errors and omissions arise from want of study of the fossil in situ, and from want of acquaintance with its yarious states of preservation. Trivial errors of this kind are his referring to my photograph in Plate III. of the "Dawn of Life," as if it were natural size, and his stating that the larger specimens have fifty laminæ, whereas they often have more than a hundred. More important is his failing to appreciate aright the occurrence of Eosöon in certain layers of regu larly bedded limestones, the rounded or club-shaped forms of the more perfect specimens, the manner in which the layers become conflient at the edges of the forms, as described by Si W. E. Logan and myself, or the amount of crushing and fracture which most of the specimens exhibit. Thus he fails to convey any adequate idea of the Stromatoporoid forms and mocie of occurrence of the organism, or indeed of its general character and probable mode of growth. Further, he treats it from the first as a mere laminated aggregate of calcite and serpentine, without reference to its occurrence in any other state, and also without reference to the fragmental limestones in part made up of its remains. He objects strongly to the want of definitenes: of form and distribution in the chambers and connecting passages, without making allowance for defects of preservation, cr mentioning the similar want of defined form in some Stromato pora. He admits, however, that the modern Carpenteria and its allies are in some respects equally indefinite. He furtherobjects to the impossibility of detecting regular pis ary chambers like those in modern foraminifera, but seems not to be aware that, as I have recently shown, some Stromatopore originate in a vesicular, irregular mass of cells, and that in Loftusia, both the eocene $\dot{L}$. Persica and the carboniferous L. Columbiana, the primary chamber is represented by a merely cancellated nucleus.

2. With reference to the finely tubulated proper wall of Eozöon, he has fallen into an error scarcely excusable in an observer of his experience, except on the plea of insufficient access to specimens. He confounds the proper wall with the chrysotile veins traversing many of the specimens, and obviously more recent than the bodies whose fisiures they fill. That he does 50 is apparent from his stating that the proper wall structure sometimes crosses the bands of serpentine and calcite, and also that it presents a series of parallel four-sides prisms, whereas, when at all perfectly preserved, it shows a series of cylindrical threads penetrating a calcite wall. Tha some of his specimens have contained the proper wall fairly preserved is obvious from his own figures, in which it is possible to recognise botb this structure and chrysotile veins, though confounded by him under the same designation. He objects, somewhat naively, that many of the chambers fail to exhibit this nummuline wall, and that it sometimes presents a ragged appearance or is altogether opaque. In point of fact it can appear distinctly, either in decalcified specimens or in slices, only when the minute tubes are filled with some substance optically distinguishable from calcite, or not acted on by dilute acid. When the proper wall is merely calcareous (and I have specimens showing that it is often in this state, and without any serpentine in its pores), its structure is ordinarily invisible, and it is the same when the calcareous skeleton has from any cause lost its transparency or has been replaced by some other mineral substance. Even in thickish slices, the tubes, thongh filled with serpentine, may be so piled on one another as to be indistinct. All this may be seen in tertiary Nummu lites. When wholly calcareous their tubulation is often quite invisible, and when imperfectly injected with glauconite o: other silicates, they often present a very irregular appearance. If Prof. Moebius will study the Nummulites injected with glauconite from Kempten, ${ }^{2}$ Bavaria, in addition to the casts of Polystomella from the Agean, to which he refers, he will be better able to appreciate these points. It may be worth repeating here that, in examining the original specimens of Eozöon, I did not recognise the proper wall. I did not doubt that it must have existed in some form, since I could easily detect the canals in the isupplemental skeleton; but I did not wonder at its non-appearance, knowing the chances against its preservation in a recognisable form. Its discovery was due to the subsequent investigations of Dr. Carpenter. ${ }^{3}$

3. To the canal system, Prof. Moebius does more justice and admits its great resemblance to the forms of this structure, in modern Foraminifera. This indeed appears from his own figures, which well show how wonderfully this structure has

\section{${ }^{x}$ See Foumal of London Geol. Soc., January, $\times 878$.} 2 I

3 It may deserve mention here that the carboniferous Fusulina very rarely shows it tubulated wall, and that Dr. Carpenter had maintained its Nummuline affinities before he obtained specimens showing this particular structure Strucfures so delicate as these are indeed only preserved exceptionally in fossil specimens. 
been preserved, and how nearly it resembles the similar parts of modern Foraminifera. He thinks, however, that these round and regularly branching forms are rather exceptional, which is a mistake; though it is true that the sections of the larger canals are often somewhat flattened, and that they become. flat where they branch. They are also sometimes altered by the vicinity of veinlets or fractures, or by minute mineral segregations in the surrounding calcite, accidents to which all similar structures in fossils are liable. Another objection, not original with him, is derived from their unequal dimensions. It is true that they are very unequal in size, but there is some definiteness about this. They are larger in the thicker and earlier formed layers, smaller or even wanting in the thinner and more superficial. In some slices the thicker trunks only are preserved, the slender branches having been filled with dolomite or ealcite. It is difficult, also, to oblain, in any slice or any surface, the whole of a group of canals, 1 Further, as I have shown, the thick canals sometimes give off groups of very minute tubes from their sides, so that the coarser and finer canals appear intermixed. These appearances are by no means at variance with what we know in other organic structures. Another objection is taken to the direction of the canals, as not being transverse to the lamina but oblique. This, however, may be dismissed, since Moebius has of course to admit that it is not unusual in modern Foraminifera. It may be added that some of the appearances which puzzled Moebius, and which are represented in his figures, evidently arise from fractures displacing parts of groups of canals, and from the apparently sudden truncation of these at points where the serpentine filling gives place to calcite. It would also have been well if he had studied the canal systems of those Stronca. topora which have a secondaiy or supplemental skeleton, as Canostroma and Caunopora.

4. A fatal defect in the mode of treatment pursued by Mocbius is that he regards each of the structures separately, and does not sufficiently consider their cumulative force when taken together. In this aspect, the ease of Eozöon may be presented thus: ( $I$ ) It occurs in certain layers of widely distributed limestones, evidently of aqueous origin, and on other grounds presumably organic. (2) Its general form, lamination, and chambers, resemble those of the silurian Stromatopora and its allies, and of such modern sessile foraminifera as Carpenteria and Polytrema. (3) It shows under the microscope a tubulated proper wall similar to that of the Nummulites, though of even finer texture. (4) It shows also in the thicker layers a secondary or supplemental skeleton with canals. (5) These forms appear more or less perfectly in specimens mineralised with very different substances. (6) The structures of Eozöon are of such generalised character as might be expected in a very early Protozoan. (7) It has been found in various parts of the world under very similar forms, and in beds approximately of the same geological horizon. (8) It may be added, though perhaps not as an argument, that the discovery of Eozöon affords a rational mode of explaining the immense development of limestones in the Laurentian age; and on the otber hand that the various attempts which have been made to other hand for the structures of Eozöon on other hypotheses than that of organic origin have not been satisfactory to chemists or maineralogists, as Dr. Hunt has very well shown.

Prof. Moebius, in summing up the evidence, lhints that Di: Carpenter and myself have leaned to a subjective treatment of Eozoon, representing its structure in a somewhat idealised manner. In answer to this it is necessary only to say that we have given photographs, nature-prints, and camera-tracings of specimens actually in our possession. We have not thought it desirable to figure the most imperfect or badly preserved specimens, though we have taken pains to explain the nature and mens, though defects. Of course, when attempts at restoration have been made, these must be taken as to some extent conjectural; but so far as these have been attempted they have consisted merely in the effort to eliminate the accidental conditions of fossilised bodies, and to present the organism in its original perfection. Such restorations are not to be taken as evidence, perfection. jillustrations to enable the facts to be more easily understood. It is to be observed, however, that in the study of such fossils as Eozöon, the observer must expect that only a small proportion of his specimens will show the structures with any approach to perfection, and that comparison of many speci. mens prepared in different ways may be necessary in order to

I have succeeded best in this by etching the surface of broken specimens understand any particular feature. A single figure or a short description may thus represent the results of days spent in the field in collecting, of careful examination and selection of the specimens, of the cutting of many slices in different directions, and of much study of these with different powers and modes of illumination. My own collection contains hundreds of preparations of "Eozöon, each of which represents perhaps hours of labour and study, and each of which throws some light more or less important on some feature of structure. The results of labour of this kind are unfortunately ve:y liable to be regarded as subjective rather than objective by those who arrive at con. clusions in easier ways.

Taken with the above cautions and explanations, the memoir of Prof. Moebius may be regarded as an interesting and useful illustration of the structures of Eozöon, though from a point of view somewhat too limited to be wholly satisfactory.

\section{THE COLOURS OF DOUBLE STARS}

IN a recent number of the Bulletin de l'A cadémie roy'ale de Beloique, M. Niesten, of the Brussels Observatory, has pub. lished some interesting details relating to the colours of double stars, to which subject he has given special attention for a considerable time past. When comparing the periodicity of solar. spots with the longitudes of planets in the ecliptic, Messrs. De la Rue, Balfour Stewart, and Loewy had found that a distinct connection exists between solar activity and the relative positions of the different members of our planetary system. A long time ago the attention of astronomers had already been drawn to the fact that Wolf's sun-spot period of eleven years coincides witl. the period of Jupiter's revolution rund the sun. Later on Prof. Balfour Stewart pointed ont that the coincidence of tie peribeliz of Jupiter and Saturn, which occurs about every fifty-nine years, corresponds to another one of Wolf's spot.periods.

If, therefore, the relative positions of the planets with regari to the sun bave some infuence upon the activity of that luminary, the question is justifiable whether on the other hand the influence of the sun upon the planets might not be apparent through some slight changes in their colour. There is no doubt that the colours of the planets actually do change; their brightness increases and decreases according to their position near the perihelion or aphelion. In the case of Jupiter changes of colour have been repeatedly observed, and they seem to coincide with the sun-spot periods. At the last opposition of Mars, when the planet was near its perihelion, it seemed to be less ruddy than usual: Uranus, which was generally described as shining with pale bluish light, is now, when it is approaching its perihelion, remarkable by its bright white lustre.

These relations between the sun and the planets induced $M$. Niesten to search for similar relations among the double stars and specially to try to answer the question whether the changes of colour which have taken place in several double-star systems are in any way connected with the relative position of the com pouents of a double star. For this purpose he collected the observations of astronomers who have given special attention to the colours of stars, and catalogued the colours of the stars visible in our horizon. It was found that many double-stars have not changed in colour since they were first observed, while others in a period of more or less considerable duration have shown 2 series of changes of colour, which seem to follow a. defmite law. The changes of colour were particularly remarkable in those double stars which possess great velocity of revolution. M. Niesten gives a table in which the different colours of twenty double stars of known period and periastrium, i.e., the colours of the principal star and of the companion, as observed. at different periods, are compiled. From M. Niesten's discussion of the facts revealed by this table, ne will give that relating to the first two double-star systems by way of example.

In $70 p$ Ophiuchi, the period of revolution of which is $94^{\circ} 3$ ? years, and for which the periastrium occurred in 1807 , the colout of the principal star at Herschel's time (an epcch closely preceding the periastrium) was white; the star then changed in colour; passing from white, through yellow and pale topaz.coloured to golden yellow, reaching this tint about 1854 . From this period it showed a tendency to return to white, passing through yellow: and pale yellow. In $1877 \mathrm{Mr}$. Pritchard designated it as pale yellow, and afterwards as white. The companion during its revolution showed similar fluctuations of colour to those of the principal star. In the vicinity of the periastrium Herschel put it down as reddish (we must remember here that Herschel's 